\section{Emmetropisation and the aetiology of refractive errors}

DI Flitcroft

\begin{abstract}
The distribution of human refractive errors displays features that are not commonly seen in other biological variables. Compared with the more typical Gaussian distribution, adult refraction within a population typically has a negative skew and increased kurtosis (ie is leptokurtotic). This distribution arises from two apparently conflicting tendencies, first, the existence of a mechanism to control eye growth during infancy so as to bring refraction towards emmetropia/low hyperopia (ie emmetropisation) and second, the tendency of many human populations to develop myopia during later childhood and into adulthood. The distribution of refraction therefore changes significantly with age. Analysis of the processes involved in shaping refractive development allows for the creation of a life course model of refractive development. Monte Carlo simulations based on such a model can recreate the variation of refractive distributions seen from birth to adulthood and the impact of increasing myopia prevalence on refractive error distributions in Asia.

Eye (2014) 28, 169-179; doi:10.1038/eye.2013.276; published online 10 January 2014
\end{abstract}

Keywords: emmetropisation; refraction; myopia; ametropia; hyperopia; model

\section{Introduction}

The statistical study of the distribution of human refractions has a long and distinguished history. Interest in refractive distributions stems in large part from the fact that human refraction appears to be very different to many other biological variables such as height or intelligence test results, which typically display a normal (ie Gaussian) or log-normal distribution. ${ }^{1,2}$ It has been long known that human refraction has a distribution that, in statistical terms, is referred to as leptokurtotic and negatively skewed. ${ }^{3}$ This is demonstrated in Figure 1, which shows data from Sorsby's 1953 study of young male army recruits. ${ }^{4}$ Compared with a Gaussian distribution of the same mean and standard deviation, the refractive data show a great excess of subjects clustered close to the mean and also a greater degree of variation at the extremes. In adult human refraction data there is also an excess of myopes, especially high myopes, which is the source of the negative skew.

What proved particularly intriguing to early researchers in this field was that the ocular parameters that contribute to final refraction such as corneal curvature, anterior chamber depth, lens thickness, and axial length were distributed in a more typically Gaussian manner. Steiger calculated the expected refractive distribution if the biometric components of refraction were randomly associated and this is shown in Figure 1 as the solid line. ${ }^{5}$ The excess of emmetropes (or perhaps more accurately low hyperopes and emmetropes) in human populations led to the suggestion that a mechanism exists to regulate eye growth so as to minimise refractive errors. ${ }^{6}$ For many years this process was largely hypothetical, but in recent years a number of longitudinal studies have provided direct evidence for such a mechanism in human infants. ${ }^{7-9}$ Animal studies have provided clear evidence of the mechanisms that might drive this process. It has now been demonstrated, in a wide range of species, that the retina is able to detect and use hyperopic and myopic defocus to control eye growth. ${ }^{10-12}$

As will be explored in this paper, the combination of a leptokurtotic and negatively skewed distribution of adult refractions arises from two apparently conflicting tendencies. First, the existence of a mechanism to control eye growth during infancy so as to bring

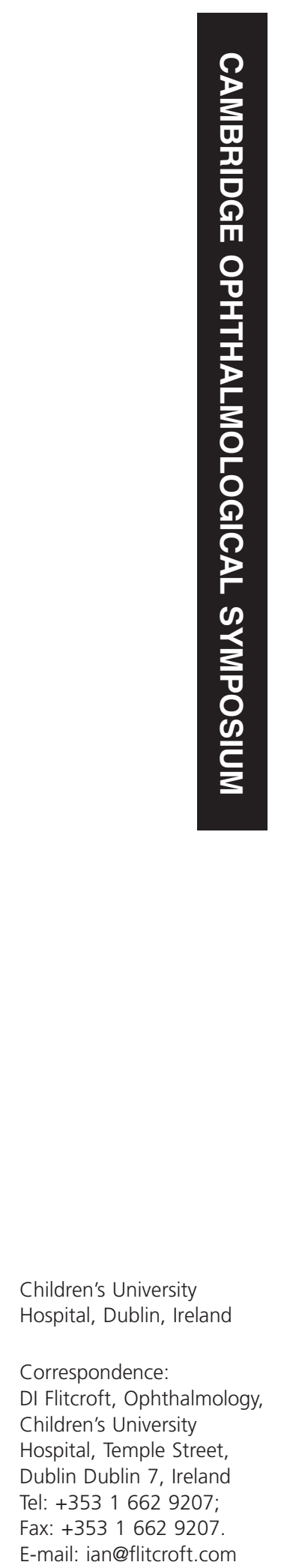

Received: 20 October 2013 Accepted: 31 October 2013 Published online: 10 January 2014 


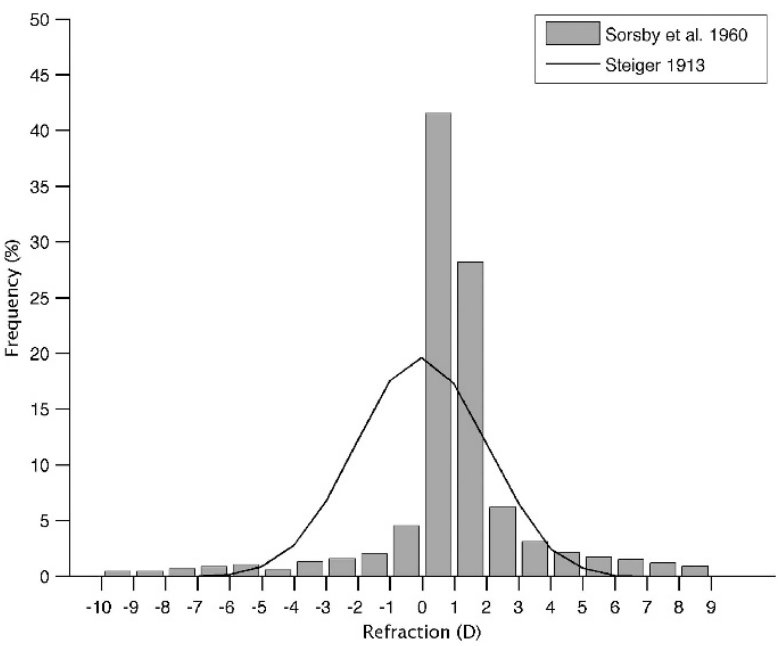

Figure 1 A representation of the refractive data from Sorsby et $a l^{4}$ and a prediction for the distribution of human refraction based on an uncorrelated combination of ocular components as measured by Steiger. ${ }^{5}$

refraction towards emmetropia/low hyperopia (ie emmetropisation) and second, the tendency of many human populations to develop myopia during later childhood and into adulthood. The distribution of refraction therefore changes with age. Although the process of emmetropisation does not appear to have changed in the past few decades, the prevalence of myopia has increased dramatically. ${ }^{13-16}$ This had led to significant changes in the distribution of adult refractions over time and geographically. Analysis of the processes involved in shaping refractive development allows for the creation of a life-course model of refractive development, as presented below. Monte Carlo simulations based on this model can recreate the wide variation in refractive distributions seen from birth to adulthood and the impact of increasing myopia prevalence on refractive error distributions in Asia.

\section{The development of human refraction errors over time}

To understand the relevance of emmetropisation to the aetiology of human refractive errors it is necessary to first define how refraction develops from birth all the way into adulthood.

\section{Development of refraction up to age 6}

At birth neonates display a wide range of refractions, which are distributed in the typical Gaussian pattern of so many other biological variables. ${ }^{9,17,18}$ This distribution undergoes a shift in mean and a substantial reduction in standard deviation within the first year. ${ }^{9}$ During this phase of eye growth there are changes in all the major determinants of refractive power namely: corneal curvature, $^{19}$ axial length, ${ }^{20}$ and lens power. ${ }^{21}$ The reduction in hyperopia is more than can be attributed to simple scaling effects (or passive emmetropisation) ${ }^{22}$ and appears to be attributable to modulation of axial growth. Like the reduction in spherical refractive error, there is also a marked reduction in astigmatism over the first few years $^{23}$ that appears to be independent of the change in spherical refractive error. ${ }^{7}$

Figure 2 shows four distributions of refraction from two different studies ${ }^{9,24}$ from 3 months of age to 3.5 years. During this time three separate processes can be observed. First, there is a progressive shift in mean refraction from $+2 \mathrm{D}$ to approximately $+0.75 \mathrm{D}$. Second, there is a significant reduction in the standard deviation or variability of refraction. Finally, although at this age the population is still approximating a Gaussian distribution, the subjects falling outside the best-fit Gaussian are predominantly hyperopic (hatched in grey in Figure 2), leading to a positively skewed distribution. These higher hyperopes appear to have failed to emmetropise or to be doing so very slowly. Effectively these hyperopes have been 'left behind' as the rest of the population has been regulated towards low hyperopia/ emmetropia.

Emmetropisation continues at a slower rate after this early rapid phase and by 6 years of age most populations display a definitely leptokurtotic distribution, although unlike adult populations this remains positively skewed (ie an excess of hyperopes, as shown in Table 1). At this age, the rate of myopia is low even in countries such as Japan that display much higher rates of myopia in older children/adults than are seen in Australia or European countries. The mean refraction is hyperopic in all three studies but it is lowest (closest to emmetropia) in Japan. If emmetropisation is considered to be the process whereby human refractive errors are minimised, then this process would appear to be largely complete in most populations by this age in terms of spherical refractive error, astigmatism, and anisometropia. 23,25

\section{Refractive development after 6 years of age}

After the age of 6 , refraction starts to display divergent patterns of refractive development. In some populations, such as Australia ${ }^{26}$ and the South Pacific island of Vanuatu, ${ }^{27}$ emmetropisation appears to continue and the population becomes even more leptokurtotic with a low incidence of myopia and hyperopia. In most populations that have been studied to date, an opposite pattern is observed with an increasing level of myopia leading to increased variance, reduced leptokurtosis, and a negative skew, as opposed to the positive skew observed in 

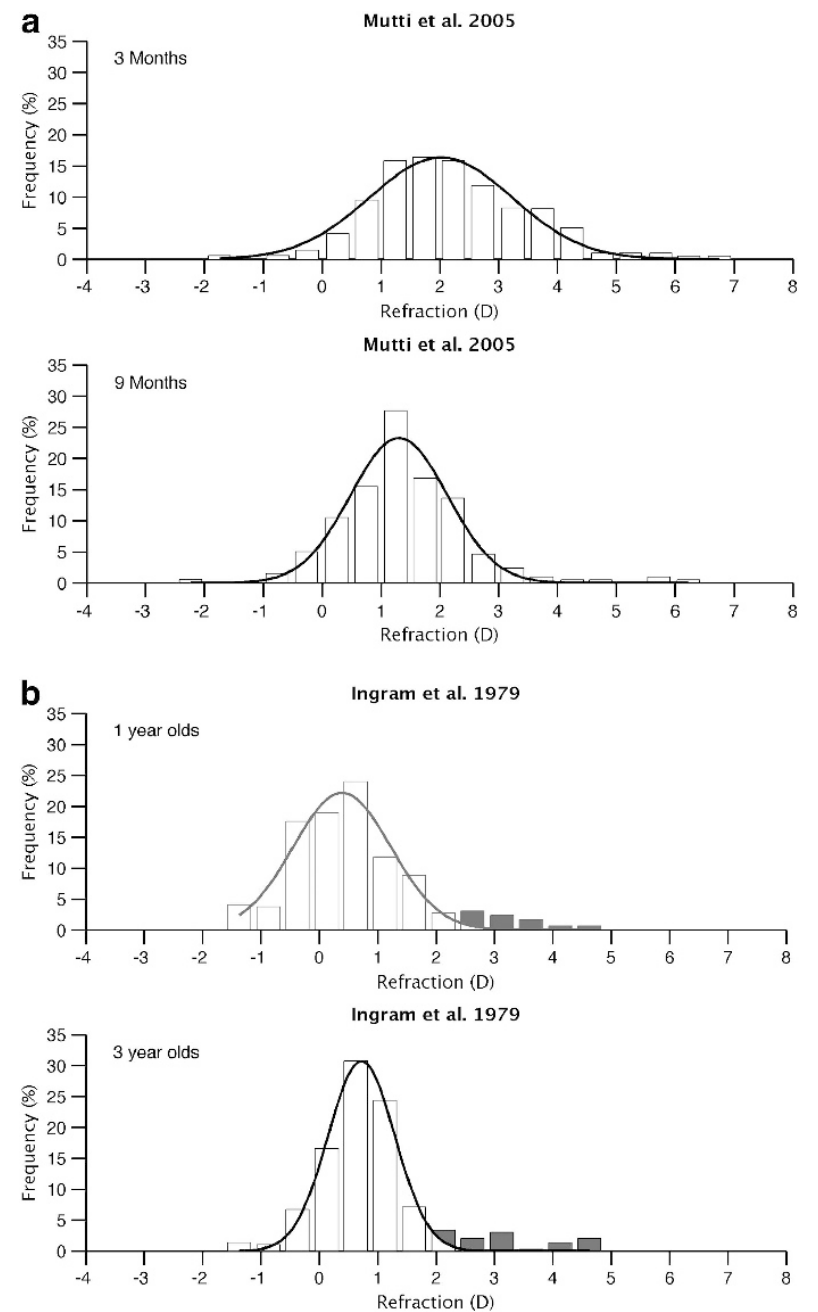

Figure 2 Four distributions of refraction from two different studies ((a) Mutti et $a l^{9}$ and (b) Ingram and Barr ${ }^{24}$ ) from 3 months of age to 3.5 years. (a) 3-9 months. (b) 1-3 years.

Table 1 Distribution parameters of human myopia in three different countries at 6-7 years of age

\begin{tabular}{lcccc}
\hline Study & $\begin{array}{c}\text { Age } \\
\text { (years) }\end{array}$ & $\begin{array}{c}\text { Mean } \\
\text { (D) }\end{array}$ & $\begin{array}{c}\text { Kurtosis } \\
\text { index }\end{array}$ & $\begin{array}{c}\text { Skew } \\
\text { index }\end{array}$ \\
\hline Watanabe et al (Japan) & 6 & 0.96 & 11.50 & 1.73 \\
Ojaimi et al (Australia) & $6-7$ & 1.26 & 14.4 & 1.27 \\
$\begin{array}{l}\text { French } \text { et al (Northern } \\
\text { Ireland subjects) }\end{array}$ & $6-7$ & 1.41 & 7.2 & 2.2 \\
\hline
\end{tabular}

younger cohorts. This is most apparent in eastern populations with a high prevalence of myopia.

Figure 3 shows data for 12-13-year-olds from Australia, northern Ireland ${ }^{26,28}$ and 11-year-olds from Japan. Whereas the Australian population has a highly leptokurtotic distribution with a low incidence of both hyperopes and myopes, the North Ireland population has retained a greater proportion of hyperopes and acquired more myopes, and thereby leading to a negatively skewed population with less kurtosis than was apparent at the age of 6 years. The Japanese population, although slightly younger, shows the highest proportion of myopia of these three groups. Figure 4 shows the changes in mean refraction and standard deviation of refraction for boys and girls in the CLEERE (Collaborative Longitudinal Evaluation of Ethnicity and Refractive Error) study from 6 to 14 years of age. ${ }^{29}$ Despite a relatively small shift in the mean refraction over this 8-year period, there is a very large increase in the variability of refraction despite the low rate of myopia development in this study compared to eastern populations.

In the Far East where rates of myopia are rising fastest there is evidence that the shift towards myopia starts as early as 6 years of age. ${ }^{15,30}$ What aspect of refractive development is driving the recent rises in myopia prevalence? A study of school children conducted over 13 years (from 1984 to 1996) in Japan provides a clear indication that the increasing levels of myopia observed during this period were not a reflection of any disruption of early emmetropisation. ${ }^{30}$ Among 17-year-olds the prevalence of myopia increased during the study period from 49.3 to $65.6 \%$, but this divergence only appeared after the age of 5 years, as shown in Figure 5. Certain eastern urban populations now display markedly skewed distributions with a high prevalence of myopia (Figure 6), although the prevalence remains lower in rural populations. ${ }^{31,32}$

The onset of myopia after the age of 6 has been observed to be associated with a greatly increased rate of myopic shift after several years of relatively stable refraction or slowly declining refraction. ${ }^{33,34}$ The early phase of progression follows an approximately linear course, ${ }^{35}$ but slows after several years and usually asymptotes towards a stable myopic refraction. This process has been found to be very well described by a double-exponent model that fits a range of different myopia onset and progression profiles. ${ }^{33}$ Despite the vast literature on the epidemiology of myopia, the triggers for the sudden initial acceleration around the time of myopia onset and the mechanisms responsible for arresting this process remain unknown.

The phase of myopia development and progression commences in childhood but persists well into adulthood. ${ }^{36}$ In studies of myopia progression it is apparent that the primary growth response is increasing axial length, ${ }^{37-39}$ even when the onset occurs in adults. ${ }^{40}$

In later life, refractive changes appear to primarily reflect changes in the optical power of the lens rather than axial length. The lens continues to grow during 

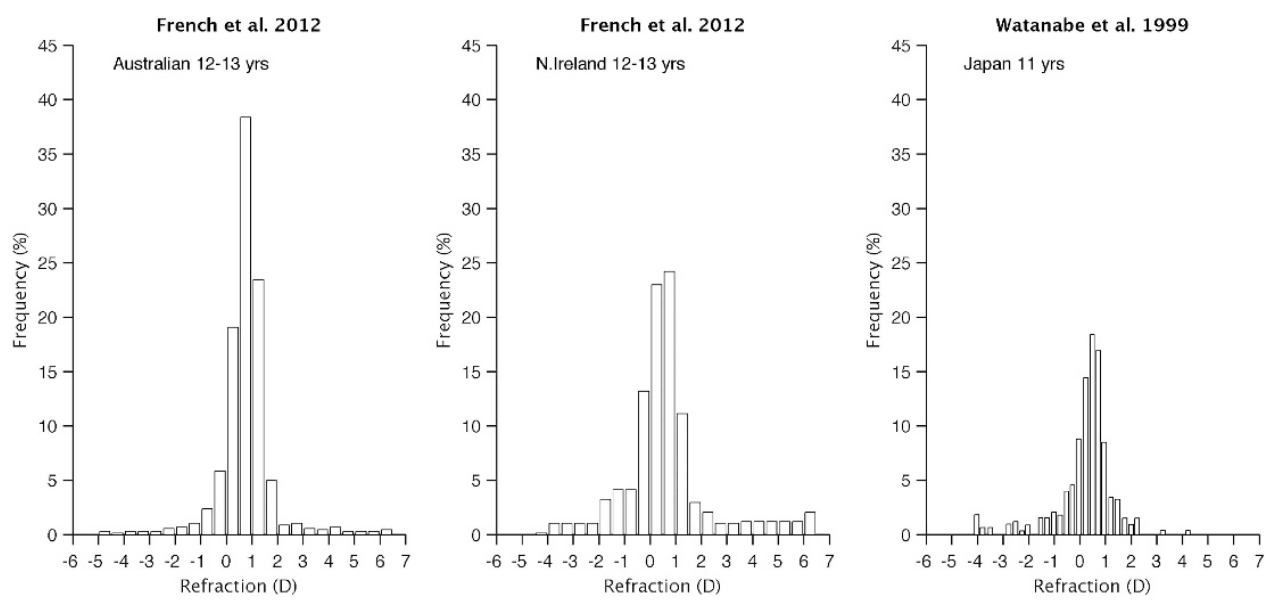

Figure 3 Histograms of the distribution of refraction in 11-13 years in Australia, Northern Ireland, and Japan.

Zadnik et al 2003
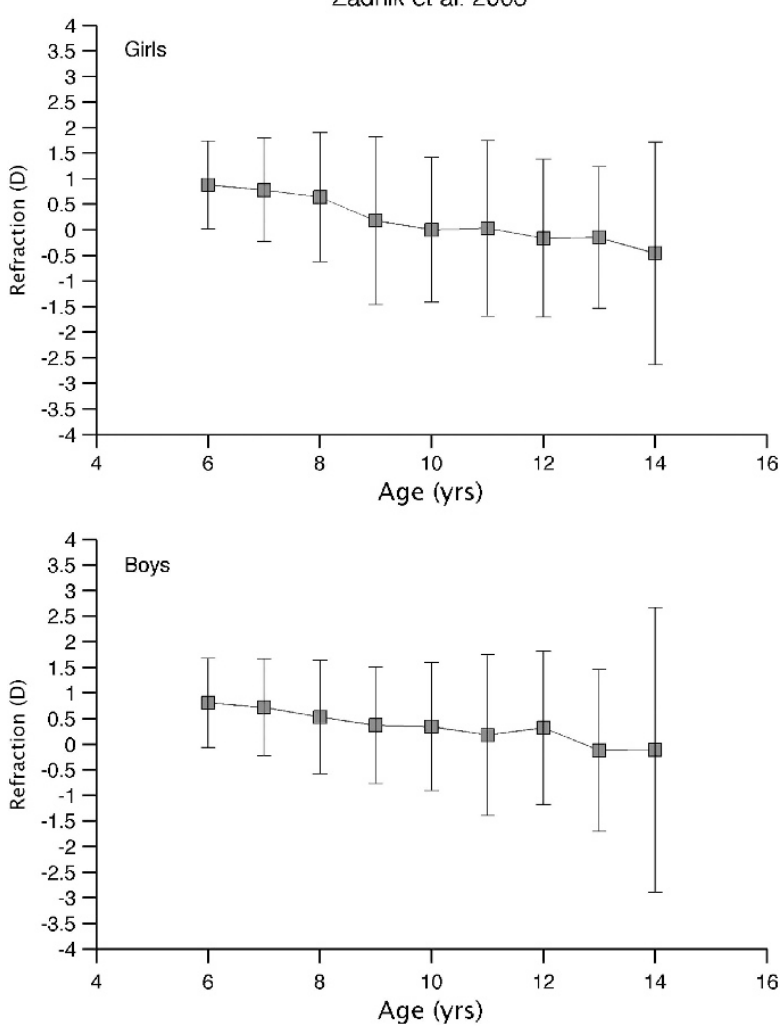

Figure 4 Mean and standard deviation of refraction from the ages of 6-14 in the CLEERE (Collaborative Longitudinal Evaluation of Ethnicity and Refractive Error) study (Zadnik et $a l^{29}$ ).

adult life and also undergoes changes in refractive index with time. The balance of these opposing factors gives rise to the lens paradox, whereby the overall refractive power of the eye remains relatively stable. ${ }^{41,42}$ In later life the development of cataracts can lead to refractive shifts, typically in a myopic direction. ${ }^{43}$

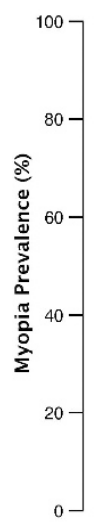

Matsumura and Hirai, 1999

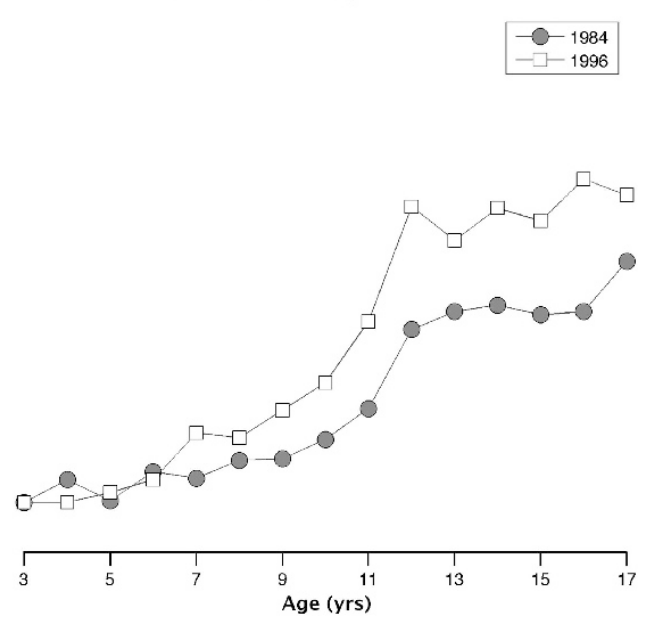

Figure 5 Prevalence of myopia in Japanese school children from ages 3-17 over a 13-year period (1984-1996 inclusive, Matsumura and $\operatorname{Hirai}^{30}$ ).

\section{If emmetropisation exists, how can we explain the existence of refractive errors?}

When considering the aetiology of refractive errors it is important to appreciate that emmetropisation is only one of many homeostatic or disruptive processes affecting eye growth from conception to adulthood. ${ }^{44}$ By the age of 6 the two principal determinants of refraction are the refraction at birth and the degree of emmetropisation that has occurred in the intervening years. The presence of a significant refractive error at age 6 requires one of the following scenarios to apply: an initial refractive error too great to be corrected by emmetropisation, an initial refraction within the normal range but deficient emmetropisation, or a combination of both of these. Refractive errors that are present at age 6 can therefore be 


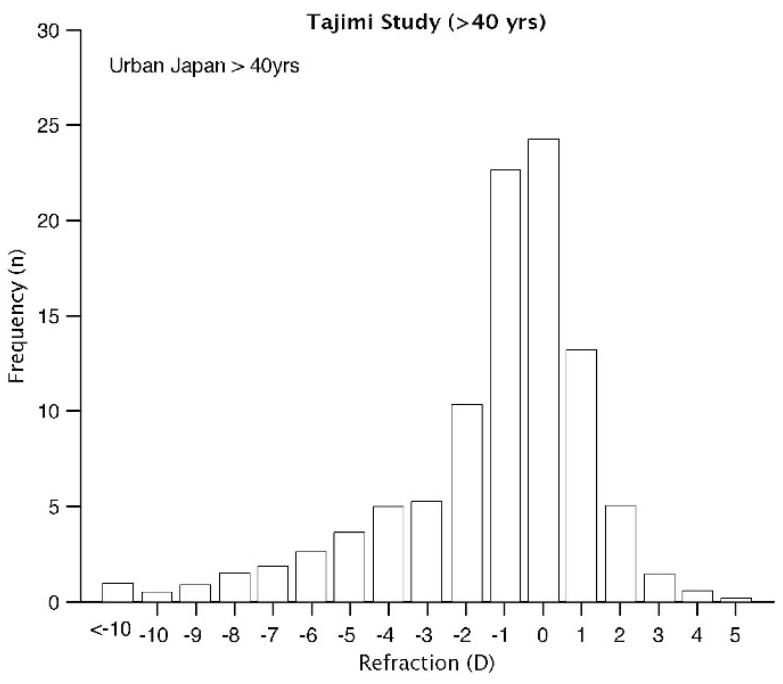

Figure 6 Distribution of refraction in adult population in Japan with a myopia prevalence showing a highly skewed distribution that has lost the classical feature of leptokurtosis seen, for example, in Figure 1.

considered as primary failures of emmetropisation. ${ }^{44}$ The overall variation of refraction and the proportion of significant ametropes are lowest at this age; therefore, it can be concluded that primary failure of emmetropisation is not the dominant factor in the aetiology of refractive errors as a whole. It is however clear that hyperopes and myopes have a different life course. The positive skew of the refractive distribution at age 6 indicates that most hyperopia arises from the persistence of infantile hyperopia due a failure of emmetropisation. The low incidence of myopia at age 6 compared to older ages indicates that the vast majority of myopia develops in eyes that have successfully emmetropised earlier in life. Myopia is therefore most commonly due to a secondary failure of the emmetropisation mechanisms to maintain emmetropia/ low hyperopia.

Another factor that might also contribute to the aetiology of refractive errors is stochastic influences on eye growth. Such influences are well described in biological systems and can be manifested at a phenotypic or genetic level. ${ }^{45}$ The existence of such stochastic factors can be inferred from the existence of anisometropia and, to a lesser extent, discordant monozygotic twins. The two eyes of an anisometrope share both the same environment and genome yet display different refractions. Early onset anisometropes may have an ocular development that is complicated by amblyopia but anisometropia often develops later and is associated with both hyperopia and myopia. Deng and Gwiazda demonstrated that the prevalence of anisometropia declines to a small extent from 6 months $(1.96 \%)$ of age to 5 years $(1.27 \%)$. Between 1 and 5 years of age many cases resolve spontaneously and almost as many arise. ${ }^{46}$ As the variation in refraction increases up to age $12-15$, so too does the amount of anisometropia (5.77\%). ${ }^{25}$

Anisometropia is also associated with the magnitude of refractive error, increasing in frequency with increasing myopia, hyperopia, and astigmatism. ${ }^{25,47}$ Loss of wellregulated patterns of growth from age 5-6 years therefore manifests as increased variability between subjects and between the two eyes of a single subject.

A similar pattern is seen in monozygotic twins that show increased discordance with increasing refractive error. $^{48,49}$ Table 2 shows the variation between refractive error and intra-pair difference in monozygotic twins from Sorsby et al. ${ }^{48}$ There is a significant association between the refractive error and the degree of refractive discordance with the discordance increasing with absolute refractive error (Fisher's exact test, two-tailed $P=0.016)$.

\section{Clinical examples of a failure of emmetropisation}

Large congenital refractive errors do exist but are rare ${ }^{50}$ and often associated with genetic disorders. ${ }^{51,52}$ Examples of clearly genetic congenital refractive errors include the congenital and non-progressive myopia associated with Stickler's syndrome ${ }^{53}$ and Leber's amaurosis. ${ }^{54}$ In such cases there appears to be a strong genetic bias away from emmetropia and the large initial refractive errors remain largely unmodified by any emmetropisation mechanism.

Keeping in view the visually guided nature of emmetropisation, conditions that prevent clear vision from birth are associated with a lack of emmetropisation and a broad range of refractions. As is observed in visual deprivation studies in animals, the refraction in such children is shifted towards a myopic mean. ${ }^{55,56} \mathrm{In}$ contrast, visual deficits that are not congenital but develop in the first 3 years are associated with hyperopic errors. ${ }^{57}$ Visual deficits such as those associated with albinism and other causes of nystagmus are also associated with impaired emmetropisation and broad refractive distributions. ${ }^{58}$ Astigmatism is also greatly increased in albinism and one analysis suggests that the vertical refractive meridian, which is unaffected by the motion blur of horizontal nystagmus, may display some degree of emmetropisation. ${ }^{59}$

There is a poorly understood interaction between amblyopia and emmetropisation. Induced amblyopia in monkeys leads to hyperopia in the amblyopic eye which correlates with the density of the amblyopic deficit. ${ }^{60}$ The development of amblyopia leads to a failure in compensatory growth to imposed lenses. ${ }^{61}$ In humans the situation is less clear cut but studies have suggested that anisometropia may be a consequence of amblyopia 
Table 2 Variation between refractive error and intra-pair difference in monozygotic twins from Sorsby et al ${ }^{48}$

\begin{tabular}{lccc}
\hline Absolute refractive error $(D)$ & $\begin{array}{c}\text { Absolute intra- } \\
\text { pair differences }\end{array}$ & Number of twin pairs \\
\cline { 2 - 3 } & $<0.5 D$ & $>0.5 D$ & \\
\hline$<0.5$ & 24 & 1 & 25 \\
$>0.5$ & 37 & 16 & 53 \\
Additional breakdown of $>0.5 D$ group & & \\
$0.75-2.0$ & 30 & 9 & 39 \\
$2.25-4.0$ & 6 & 2 & 8 \\
$>4.25$ & 1 & 5 & 6 \\
\hline
\end{tabular}

There is a significant association between the refractive error and the degree of refractive discordance with the discordance increasing with absolute refractive error (Fisher's exact test, two-tailed $P=0.016$ ).

as much as a cause. ${ }^{62,63}$ Amblyopic eyes display different patterns of vitreous chamber growth to the fellow eye. ${ }^{64}$

Prematurity, even in the absence of retinopathy of prematurity, has been demonstrated to impair emmetropisation in at least a subset of children. 65,66 A more dramatic failure of emmetropisation can be observed in Down's syndrome despite the good visual acuity usually observed in this condition. ${ }^{67,68}$ It has been proposed that the apparent absence of emmetropisation in Down's syndrome would reveal the underlying pattern of genetically determined eye growth. ${ }^{69}$ The patterns of refractive development in Down's syndrome are instead highly variable and display the mathematical features of a random walk typical of a stochastic process. ${ }^{67,68}$

\section{A comprehensive model of the mechanisms involved in refractive development}

This paper has reviewed the major influences on refractive development from birth to adulthood. These are the initial refraction at birth, the efficacy and duration of the emmetropisation process in the first few years of life, the poorly understood mechanisms of myopia onset and progression, stochastic influences on eye growth, and, more rarely, sources of major genetic bias towards myopia or hyperopia. This allows the creation of a model for the development of refractive errors from birth to adulthood. This model encapsulates each of these processes in a simple mathematical form. Equation (1) provides a mathematical description of this model and Figure 7 provides an annotated explanation of each component and parameter.

$$
\begin{aligned}
R(t)= & R_{\mathrm{o}}+E_{\mathrm{g}}\left(R_{\mathrm{o}}-R_{\mathrm{s}}\right)\left(1-e^{-\frac{t}{E_{t}}}\right) \\
& +R_{\mathrm{c}}\left(0.07295^{a^{t-t_{o}}}\right)+G_{\mathrm{n}}(t)+G_{\mathrm{b}}
\end{aligned}
$$

where, $R(t)$ is the refraction at time $t ; R_{\mathrm{o}}$ is the refraction at birth; $E_{\mathrm{g}}$ is the gain of emmetropisation controller; $R_{\mathrm{S}}$ is the refractive set-point target; $E_{\mathrm{t}}$ is the emmetropisation time constant; $R_{\mathrm{C}}$ is the myopic offset; $a$, is the myopic progression shape; $t_{\mathrm{o}}$ is the myopia onset time; $G_{n}(t)$ is the growth associated biological noise; $G_{b}(t)$ is the genetic bias

In essence, this model combines the four components described above. First, the starting point of refraction at birth is captured by the term $R_{\mathrm{o}}$. Emmetropisation is captured in the simplest possible manner as an exponential model (with parameters for the gain of emmetropisation, the set-point towards which the eye grows, and a time-constant reflecting the time-limited nature of the process). The modified Gompertz formula developed by Thorn et $a l^{33}$ is included to capture the process of myopic progression as it describes this better than any other model to date. The $R_{\mathrm{c}}$ and $a$ parameters of the original model are maintained for ease of comparison but the $R_{\mathrm{c}}$ parameter is omitted as the starting refraction is determined by the first two terms. The biological noise and bias terms $\left(G_{\mathrm{n}}(t)\right.$ and $\left.G_{\mathrm{b}}\right)$ are specified as generalised functions, although in general these factors only seem to be dominant in limited range of clinical scenarios.

Equation 1 has been specified to allow calculation of refraction at a given age depending on the value of the various parameters and does not allow for interaction between the different components. This is clearly a simplification but the first three factors are largely independent on the basis that the operative factors have little or no temporal overlap. A more complete mathematical description would specify all four processes as part of a differential equation incorporating stochastic components as this would provide for the interaction between each of the processes. Such a treatment is beyond the scope of the current paper.

This model allows the simulation of the distribution of human refraction from birth into adulthood and each of the parameters can be estimated from existing clinical studies. To model a population, each of these parameters can be subjected to random variation using either a Gaussian or Beta probability function, and once again existing studies provide a basis for estimating such parameters. The following Monte Carlo simulations are based on 20000 subjects with the parameters given in Table 3 and performed using custom Matlab (Mathworks Inc., Natick, MA, USA) functions that are available from the author on request. With the exception of the variation in the gain of emmetropisation $\left(E_{\mathrm{g}}\right)$, the distributions chosen for the parameters listed in Table 3 were based on published data for such parameters ${ }^{33}$ or estimated from human distribution data from a variety of sources. As the stochastic and bias elements are dominant only in pathological situations, these elements have not been included in the following simulations. 


\section{a}

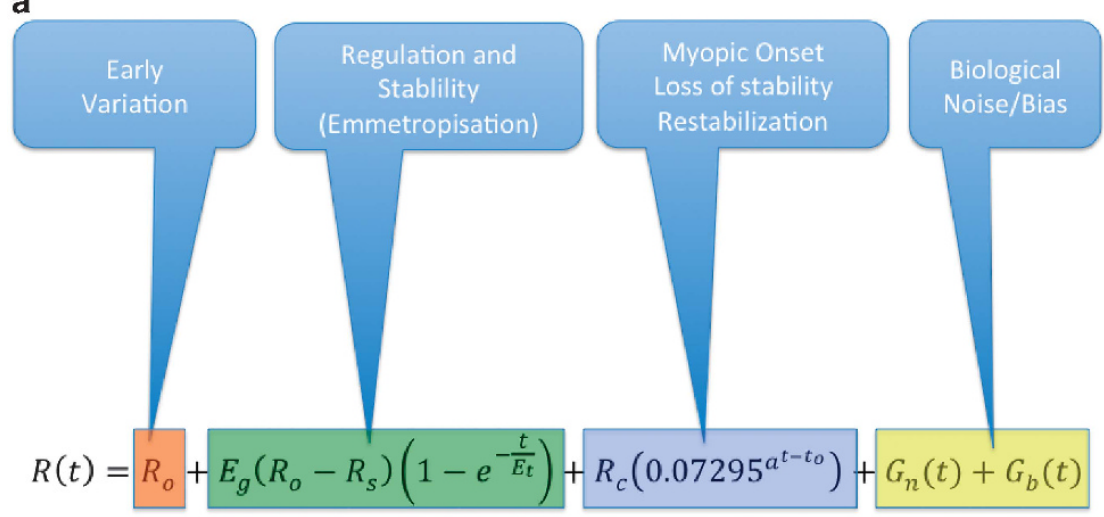

b

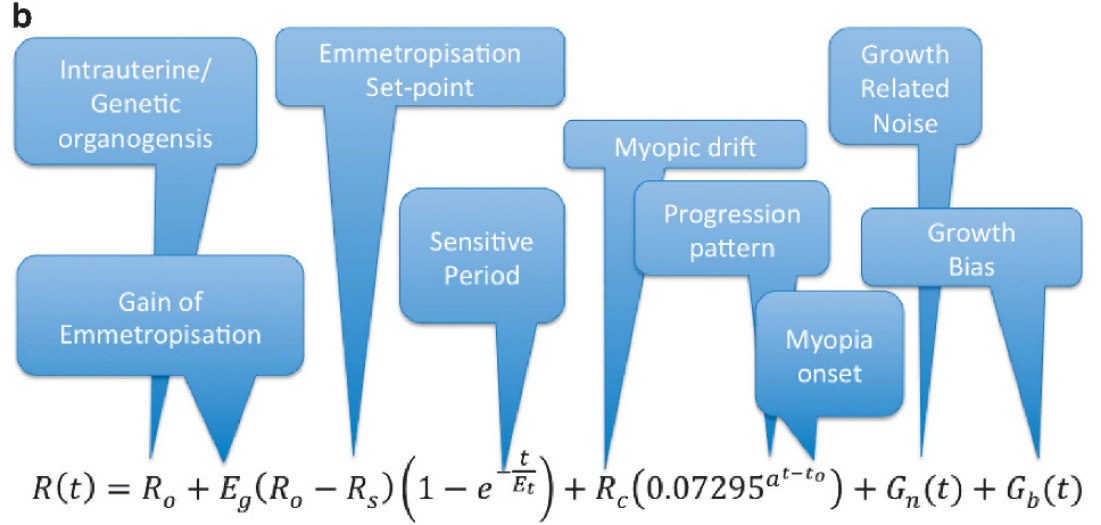

Figure 7 An annotation of equation 1 describing the biological mechanisms associated with each component of the model (a) and an annotation of equation (1) describing the biological relevance of each component parameter (b).

Table 3 Parameters and distribution models used for Monte Carlo simulations of refractive developments shown in Figures 8 and 9

\begin{tabular}{llccc}
\hline Parameter & Distribution & \multicolumn{2}{c}{ Values } & Notes/modifiers \\
\hline$R_{\mathrm{o}}$ & Gaussian & $\mu=2.5 \mathrm{D}$ & $\sigma=2.2 \mathrm{D}$ & \\
$E_{\mathrm{g}}$ & Bimodal beta & $\alpha=8$ & $\beta=0.5$ & High-gain population \\
& & $\alpha=3$ & $\beta=6$ & Low-gain population \\
$R_{\mathrm{s}}$ & Gaussian & $\mu=0.5$ & $\sigma=0.5$ & \\
$E_{\mathrm{t}}$ & Beta & $\alpha=5$ & $\beta=2$ & $2.0 \times$ Beta \\
$R_{\mathrm{c}}$ & Beta & $\alpha=1$ & $\beta=4$ & $-10 \times$ Beta \\
$a$ & Beta & $\alpha=7$ & $\beta=6$ & \\
$t_{\mathrm{o}}$ & Beta & $\alpha=1.75$ & $\beta=6$ & $5+20 \times$ Beta \\
\hline
\end{tabular}

To create the behaviour observed in human populations it proved necessary to divide the population into a proportion with a high gain of emmetropisation (90-95\% of the population) and a corresponding proportion with low gain. The variation between modern day Australian distributions (eg Figure 3), historic UK distributions (eg Figure 1), young Asian and older Asian distributions (eg Figures 3 and 6) could be created by varying the proportion of those who undergo later myopic progression (ie those who are both genetically sensitive and exposed to myopic environmental triggers). This proportion has minimal impact on refractive development in this model up to the age of 6 because of the observed age range of the $t_{\mathrm{o}}$ parameter (myopia onset parameter), but represents a dominant shape factor at older ages.

Figure 8 shows the results of Monte Carlo simulations from 3 months of age up to 6 years. The evolution of the refractive distribution from a normally distributed population with wide variation to a positively skewed leptokurtotic population closely mirrors that seen in population studies. Figure 9 extends these models from age 6 years up to age 24 years. The left-hand graphs on this figure have set $15 \%$ of the population to be susceptible to myopic progression and the right hand graphs $55 \%$. Both in terms of increasing myopia prevalence $(<-0.5 \mathrm{D})$ and the shape of the distribution these graphs also mirror the statistics of refractive distributions in low and high myopia prevalence populations.

\section{Discussion}

This analysis of emmetropisation and the development of refractive errors are intended to provide a framework for a more rational discussion and 

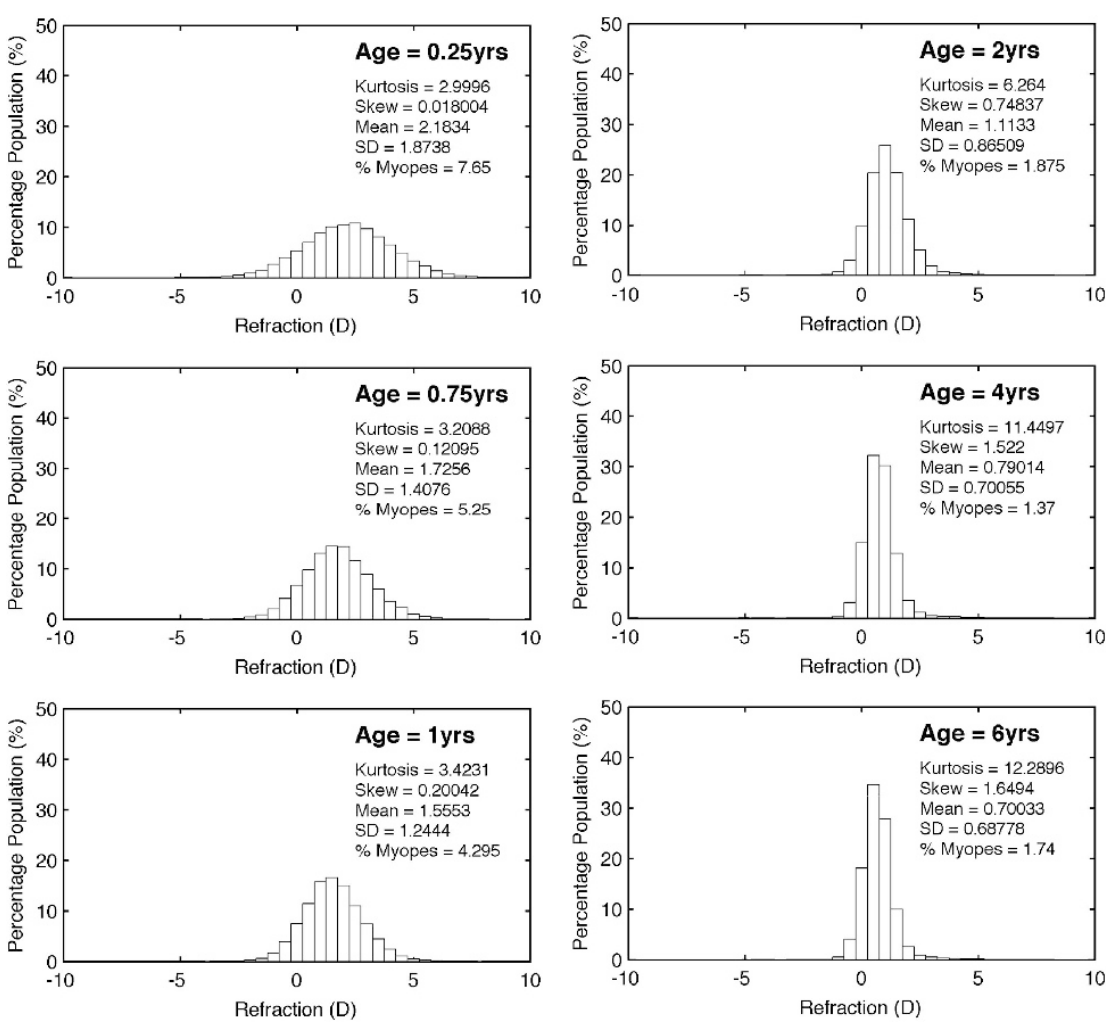

Figure 8 Results of Monte Carlo simulations of human refractive development from 3 months of age to 6 years.
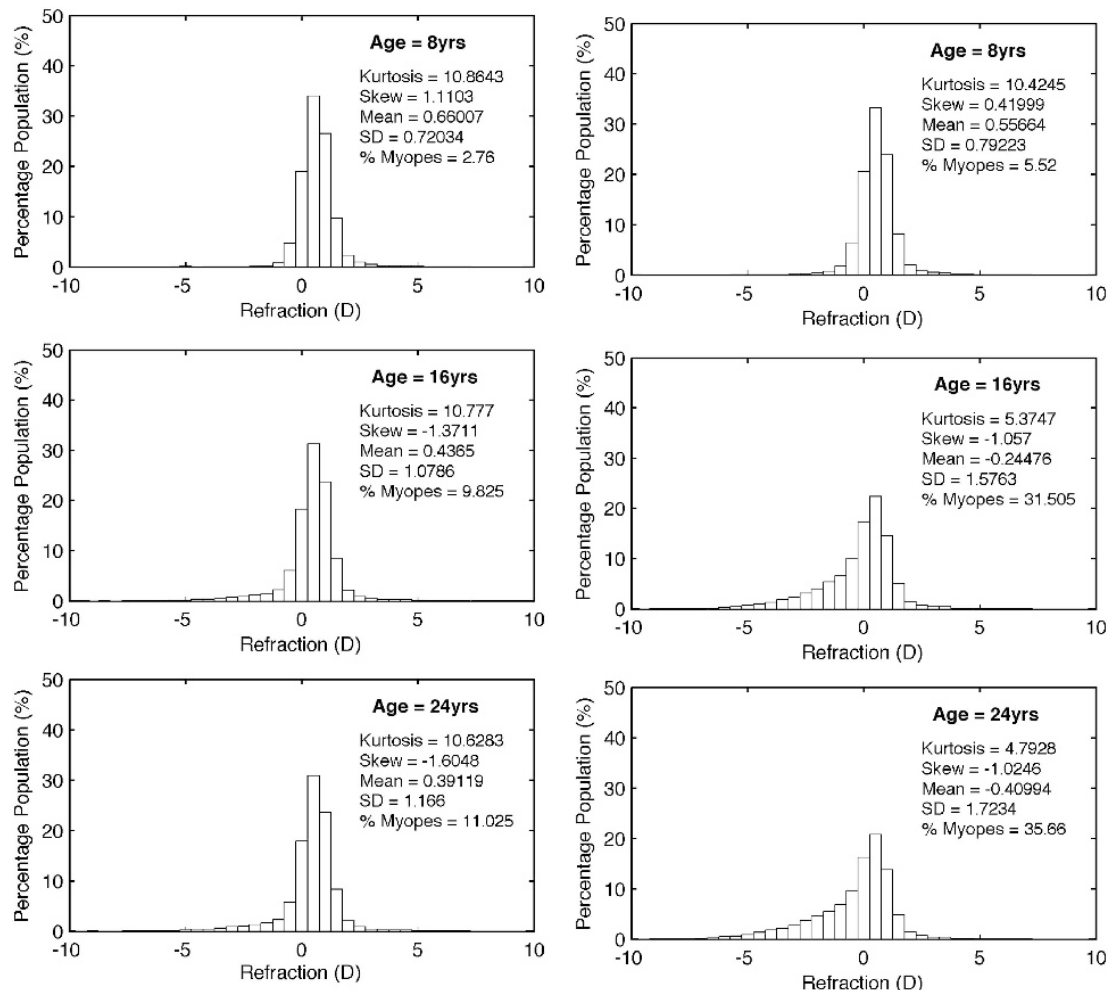

Figure 9 Results of Monte Carlo simulations of human refractive development from 8 years of age to 24 years. The left-hand panels model a population with a low tendency to develop myopia and the right-hand panels a population with a high tendency to develop myopia. 
approach to refractive errors. Since refractive error is the end result of a long, complex growth process over several decades, it is no longer valid to consider refraction in the same manner as a simple trait. Adult hyperopes and myopes errors have quite different life courses in terms of ocular development and would appear to be the result of fundamentally different processes. Furthermore, any given refractive error can be the result of a wide variety of influences. These influences include the following: where in the refractive distribution range of an eye starts at birth; the effectiveness (ie gain) and set-point of emmetropisation; the impact of stochastic factors when emmetropisation is deficient; the susceptibility to later myopiogenic factors; the exposure to such factors; and the regulation of the adolescent phase of ocular growth in axial length and lens power. Therefore, rather than accepting a single figure for the heritability of refraction we should be asking what aspects of this process are genetically determined, what aspects are essentially random (stochastic) and what aspects are influenced by visual experience or other environmental factors.

The model presented in this paper is based on welldefined, if not fully understood, phenomena within refractive development. That a single model can provide a mechanistic explanation of both the evolution of refractive distributions since birth through childhood into adulthood and the variations in refractive distribution shape seen in different adult populations is a testament to validity of the underlying concepts. The parameters also have clinical relevance and are, in the most part, measurable. The question of examining genetic and environmental contributions to refractive error may become more tangible if the different aspects of the refractive life-course encapsulated within this model and its parameters are considered in isolation.

Although the term emmetropisation is often used to describe the process where older hyperopes 'grow out of their glasses' ${ }^{70}$ it is clear from this review that true emmetropisation occurs early in life. The process of growing out of their glasses, that is observed in some but by no means all childhood hyperopes, occurs at the same age that myopia is starting to emerge. Is this late hyperopic 'emmetropisation' merely another manifestation of the processes driving myopia onset/ progression or is it an entirely different process. This is an interesting and unanswered question. If it were true and the factors driving myopia onset and progression could be determined, then such factors could be used to develop novel management strategies for the hyperopia and accommodative esotropia.

There is clear evidence from myopia intervention studies that the growth of the older human eye is sensitive to optical defocus. ${ }^{71-73}$ If the human eye remains sensitive to defocus why does the later phase of eye growth lead to refractive errors, in particular myopia? An intriguing suggestion is that, as shown in tree shrews, the older eye loses the ability to respond to myopic defocus that might slow or halt eye growth but continues to be sensitive to hyperopic defocus that promotes axial elongation. ${ }^{69}$

It seems reasonable to assume that human infant emmetropisation reflects the optically guided growth mechanisms that have been identified in lens-rearing studies in animals. Both are most active early in life ${ }^{74}$ and human infants display other features that are predicted by an optically guided process. ${ }^{75,76}$ Partial hyperopic correction in infants does not seem to impair the end result of emmetropisation though it does appear to slow the process. ${ }^{77}$ In keeping with the predictions of an optically guided control model, the rate of emmetropisation has been reported to be correlated with the magnitude of the initial refractive error. ${ }^{78} \mathrm{We}$ therefore have a good animal model for emmetropisation but we do not have an animal that helps us understand how, in later childhood, eyes undergo a rapid refractive acceleration in the direction of myopia. Until we can define and understand the triggers and growth mechanisms mediating this initial acceleration and subsequent stabilisation, we cannot claim to explain the aetiology of the vast majority of myopia.

\section{Conclusion}

The bulk of emmetropisation occurs in early childhood and is largely complete by age 6 . Therefore, refractive errors that exist at this age can be considered failures of emmetropisation. The commonest refractive error at age 6 is hyperopia with both anisometropia and myopia being far less common at this age. Since the prevalence of myopia shows a marked increase in later years, only a very small proportion of myopic refractive errors can be attributed to a primary failure of emmetropisation. Therefore, an understanding of how and why emmetropisation fails will be of particular importance in understanding hyperopia rather than myopia. Anisometropia remains the least understood refractive abnormality and a fuller understanding may require the addition of chance (ie stochastic factors) to the traditional pair of nature and nurture. When considering the aetiology of refractive errors it is no longer tenable to consider refraction as a trait without considering the developmental processes involved. It is hoped that the model presented in this paper may be of assistance in bringing together different aspects of eye growth. While myopia has public health implications in the adult population, ${ }^{79}$ within paediatric ophthalmology it is hyperopia and anisometropia that create the greatest morbidity. Far less attention has been devoted 
to understanding how these conditions may be manipulated biologically than what has been given to myopia treatments. This is an imbalance that merits redress.

\section{Conflict of interest}

The author declares no conflict of interest.

\section{References}

1 Limpert E, Stahel WA, Abbt M. Log-normal distributions across the sciences: keys and clues. Bioscience 2001; 51: 341-352.

2 Sokal RR, Rohlf FJ. Biometry: The Principles and Practice of Statistics in Biological Research. 3rd edn. W.H. Freeman: New York, 1995.

3 Stenstrom S. Investigation of the variation and the correlation of the optical elements of human eyes. Am J Optom Arch Am Acad Optom 1948; 25: 496-504.

4 Sorsby A, Sheridan M, Leary GA, Benjamin B. Vision, visual acuity, and ocular refraction of young men: findings in a sample of 1,033 subjects. Br Med J 1960; 1: 1394-1398.

5 Steiger A. Die Entstehung der sphärischen Refraktionen des menschlichen Auges. Karger: Berlin, 1913.

6 Straub M. Über die Aetiologie der Brechungsanomalien des Auges und den Ursprung der Emmetropie. Graefes Arch Ophthalmol 1909; 70: 130-199.

7 Ehrlich DL, Braddick OJ, Atkinson J, Anker S, Weeks F, Hartley $\mathrm{T}$ et al. Infant emmetropization: longitudinal changes in refraction components from nine to twenty months of age. Optom Vis Sci 1997; 74: 822-843.

8 Mohindra I, Held R. Refraction in humans from birth to five years. Doc Ophthalmol Proc Series 1981; 28: 19-27.

9 Mutti DO, Mitchell GL, Jones LA, Friedman NE, Frane SL, Lin WK et al. Axial growth and changes in lenticular and corneal power during emmetropization in infants. Invest Ophthalmol Vis Sci 2005; 46: 3074-3080.

10 Wallman J, Winawer J. Homeostasis of eye growth and the question of myopia. Neuron 2004; 43: 447-468.

11 Wildsoet CF. Active emmetropization-evidence for its existence and ramifications for clinical practice. Ophthalmic Physiol Opt 1997; 17: 279-290.

12 Troilo D. Neonatal eye growth and emmetropisation-a literature review. Eye (Lond) 1992; 6(Pt 2): 154-160.

13 Vitale S, Sperduto RD, Ferris 3rd, FL. Increased prevalence of myopia in the United States between 1971-1972 and 1999-2004. Arch Ophthalmol 2009; 127: 1632-1639.

14 Tay MT, Au Eong KG, Ng CY, Lim MK. Myopia and educational attainment in 421,116 young Singaporean males. Ann Acad Med Singapore 1992; 21: 785-791.

15 Lin LL, Shih YF, Hsiao CK, Chen CJ. Prevalence of myopia in Taiwanese schoolchildren: 1983 to 2000. Ann Acad Med Singapore 2004; 33: 27-33.

16 Bar Dayan Y, Levin A, Morad Y, Grotto I, Ben-David R, Goldberg A et al. The changing prevalence of myopia in young adults: a 13-year series of population-based prevalence surveys. Invest Ophthalmol Vis Sci 2005; 46: 2760-2765.

17 Goldschmidt E. Refraction in the newborn. Acta Ophthalmol (Copenh) 1969; 47: 570-578.

18 Cook RC, Glasscock RE. Refractive and ocular findings in the newborn. Am J Ophthalmol 1951; 34: 1407-1413.
19 Inagaki Y. The rapid change of corneal curvature in the neonatal period and infancy. Arch Ophthalmol 1986; 104: 1026-1027.

20 Fledelius HC, Christensen AC. Reappraisal of the human ocular growth curve in fetal life, infancy, and early childhood. Br J Ophthalmol 1996; 80: 918-921.

21 Gordon RA, Donzis PB. Refractive development of the human eye. Arch Ophthalmol 1985; 103: 785-789.

22 Hofstetter HW. Emmetropization-biological process or mathematical artifact? Am J Optom Arch Am Acad Optom 1969; 46: 447-450.

23 Gwiazda J, Grice K, Held R, McLellan J, Thorn F. Astigmatism and the development of myopia in children. Vision Res 2000; 40: 1019-1026.

24 Ingram RM, Barr A. Changes in refraction between the ages of 1 and 3 1/2 years. Br J Ophthalmol 1979; 63: 339-342.

25 Deng L, Gwiazda JE. Anisometropia in children from infancy to 15 years. Invest Ophthalmol Vis Sci 2012; 53: 3782-3787.

26 French AN, O'Donoghue L, Morgan IG, Saunders KJ, Mitchell P, Rose KA. Comparison of refraction and ocular biometry in European Caucasian children living in Northern Ireland and Sydney, Australia. Invest Ophthalmol Vis Sci 2012; 53: 4021-4031.

27 Garner LF, Kinnear RF, McKellar M, Klinger J, Hovander MS, Grosvenor T. Refraction and its components in Melanesian schoolchildren in Vanuatu. Am J Optom Physiol Opt 1988; 65: 182-189.

28 Watanabe S, Yamashita T, Ohba N. A longitudinal study of cycloplegic refraction in a cohort of 350 Japanese schoolchildren. Cycloplegic refraction. Ophthalmic Physiol Opt 1999; 19: 22-29.

29 Zadnik K, Manny RE, Yu JA, Mitchell GL, Cotter SA, Quiralte JC. Ocular component data in schoolchildren as a function of age and gender. Optom Vis Sci 2003; 80: 226-236.

30 Matsumura $\mathrm{H}$, Hirai H. Prevalence of myopia and refractive changes in students from 3 to 17 years of age. Surv Ophthalmol 1999; 44(Suppl 1): S109-S115.

31 Liang YB, Wong TY, Sun LP, Tao QS, Wang JJ, Yang XH. Refractive errors in a rural Chinese adult population the Handan eye study. Ophthalmology 2009; 116: 2119-2127.

32 Sawada A, Tomidokoro A, Araie M, Iwase A, Yamamoto T. Tajimi Study Group. Refractive errors in an elderly Japanese population: the Tajimi study. Ophthalmology 2008; 115: 363-370.

33 Thorn F, Gwiazda J, Held R. Myopia progression is specified by a double exponential growth function. Optom Vis Sci 2005; 82: 286-297.

34 Mantyjarvi MI. Changes of refraction in schoolchildren. Arch Ophthalmol 1985; 103: 790-792.

35 Goss DA, Winkler RL. Progression of myopia in youth: age of cessation. Am J Optom Physiol Opt 1983; 60: 651-658.

36 Dirani M, Shekar SN, Baird PN. Adult-onset myopia: the Genes in Myopia (GEM) twin study. Invest Ophthalmol Vis Sci 2008; 49: 3324-3327.

37 Chung K, Mohidin N, O'Leary DJ. Undercorrection of myopia enhances rather than inhibits myopia progression. Vision Res 2002; 42: 2555-2559.

38 Chua WH, Balakrishnan V, Chan YH, Tong L, Ling Y, Quah BL et al. Atropine for the treatment of childhood myopia. Ophthalmology 2006; 113: 2285-2291.

39 Gwiazda J, Hyman L, Hussein M, Everett D, Norton TT, Kurtz D et al. A randomized clinical trial of progressive addition lenses versus single vision lenses on the 
progression of myopia in children. Invest Ophthalmol Vis Sci 2003; 44: 1492-1500.

40 McBrien NA, Adams DW. A longitudinal investigation of adult-onset and adult-progression of myopia in an occupational group. Refractive and biometric findings. Invest Ophthalmol Vis Sci 1997; 38: 321-333.

41 Brown NP, Koretz JF, Bron AJ. The development and maintenance of emmetropia. Eye (Lond) 1999; 13(Pt 1): 83-92.

42 Hemenger RP, Garner LF, Ooi CS. Change with age of the refractive index gradient of the human ocular lens. Invest Ophthalmol Vis Sci 1995; 36: 703-707.

43 Brown NA. The morphology of cataract and visual performance. Eye (Lond) 1993; 7(Pt 1): 63-67.

44 Flitcroft DI. Is myopia a failure of homeostasis? Exp Eye Res 2013; 114: 16-24

45 Raj A, van Oudenaarden A. Nature, nurture, or chance: stochastic gene expression and its consequences. Cell 2008; 135: 216-226.

46 Abrahamsson M, Fabian G, Sjostrand J. A longitudinal study of a population based sample of astigmatic children. II. The changeability of anisometropia. Acta Ophthalmol (Copenh) 1990; 68: 435-440.

47 Qin XJ, Margrain TH, To CH, Bromham N, Guggenheim JA. Anisometropia is independently associated with both spherical and cylindrical ametropia. Invest Ophthalmol Vis Sci 2005; 46: 4024-4031.

48 Sorsby A, Sheridan M, Leary GA. Refraction and its Components in Twins. Medical Research Council (Great Britain) HMSO: London, 1962.

49 Hammond CJ, Snieder H, Gilbert CE, Spector TD. Genes and environment in refractive error: the twin eye study. Invest Ophthalmol Vis Sci 2001; 42: 1232-1236.

50 Hiatt RL, Costenbader FD, Albert DG. Clinical Evaluation of Congenital Myopia. Arch Ophthalmol 1965; 74: 31-35.

51 Marr JE, Halliwell-Ewen J, Fisher B, Soler L, Ainsworth JR. Associations of high myopia in childhood. Eye 2001; 15: 70-74.

52 Marr JE, Harvey R, Ainsworth JR. Associations of high hypermetropia in childhood. Eye 2003; 17: 436-437.

53 Wilson MC, McDonald-McGinn DM, Quinn GE, Markowitz GD, LaRossa D, Pacuraru AD et al. Long-term follow-up of ocular findings in children with Stickler's syndrome. Am J Ophthalmol 1996; 122: 727-728.

54 Abouzeid H, Li Y, Maumenee IH, Dharmaraj S, Sundin O. A G1103R mutation in CRB1 is co-inherited with high hyperopia and Leber congenital amaurosis. Ophthalmic Genet 2006; 27: 15-20.

55 Rabin J, Van Sluyters RC, Malach R. Emmetropization: a vision-dependent phenomenon. Invest Ophthalmol Vis Sci 1981; 20: 561-564.

56 Raviola E, Wiesel TN. An animal model of myopia. N Engl J Med 1985; 312: 1609-1615.

57 Nathan J, Kiely PM, Crewther SG, Crewther DP. Disease-associated visual image degradation and spherical refractive errors in children. Am J Optom Physiol Opt 1985; 62: 680-688.

58 Sampath V, Bedell HE. Distribution of refractive errors in albinos and persons with idiopathic congenital nystagmus. Optom Vis Sci 2002; 79: 292-299.

59 Wildsoet CF, Oswald PJ, Clark S. Albinism: its implications for refractive development. Invest Ophthalmol Vis Sci 2000; 41: $1-7$.
60 Kiorpes L, Wallman J. Does experimentally-induced amblyopia cause hyperopia in monkeys? Vision Res 1995; 35: 1289-1297.

61 Smith 3rd, EL, Hung LF, Harwerth RS. Developmental visual system anomalies and the limits of emmetropization. Ophthalmic Physiol Opt 1999; 19: 90-102.

62 Lepard CW. Comparative changes in the error of refraction between fixing and amblyopic eyes during growth and development. Am J Ophthalmol 1975; 80: 485-490.

63 Nastri G, Perugini GC, Savastano S, Polzella A, Sbordone G. The evolution of refraction in the fixing and the amblyopic eye. Doc Ophthalmol 1984; 56: 265-274.

64 Burtolo C, Ciurlo C, Polizzi A, Lantier PB, Calabria G. Echobiometric study of ocular growth in patients with amblyopia. J Pediatr Ophthalmol Strabismus 2002; 39: 209-214.

65 Saunders KJ, McCulloch DL, Shepherd AJ, Wilkinson AG. Emmetropisation following preterm birth. $\mathrm{Br} J$ Ophthalmol 2002; 86: 1035-1040.

66 Ricci B. Refractive errors and ocular motility disorders in preterm babies with and without retinopathy of prematurity. Ophthalmologica 1999; 213: 295-299.

67 Cregg M, Woodhouse JM, Stewart RE, Pakeman VH, Bromham NR, Gunter HL et al. Development of refractive error and strabismus in children with Down syndrome. Invest Ophthalmol Vis Sci 2003; 44: 1023-1030.

68 Haugen OH, Hovding G, Lundstrom I. Refractive development in children with Down's syndrome: a population based, longitudinal study. Br J Ophthalmol 2001; 85: 714-719.

69 Siegwart Jr., JT, Norton TT. Perspective: how might emmetropization and genetic factors produce myopia in normal eyes? Optom Vis Sci 2011; 88: E365-E372.

70 Lowery RS, Hutchinson A, Lambert SR. Emmetropization in accommodative esotropia: an update and review. Compr Ophthalmol Update 2006; 7: 145-149.

71 Phillips JR. Monovision slows juvenile myopia progression unilaterally. Br J Ophthalmol 2005; 89: 1196-1200.

72 Kakita T, Hiraoka T, Oshika T. Influence of overnight orthokeratology on axial elongation in childhood myopia. Invest Ophthalmol Vis Sci 2011; 52: 2170-2174.

73 Cheng D, Schmid KL, Woo GC, Drobe B. Randomized trial of effect of bifocal and prismatic bifocal spectacles on myopic progression: two-year results. Arch Ophthalmol 2010; 128: $12-19$.

74 Howlett MH, McFadden SA. Emmetropization and schematic eye models in developing pigmented guinea pigs. Vision Res 2007; 47: 1178-1190.

75 Flitcroft DI. The lens paradigm in experimental myopia: oculomotor, optical and neurophysiological considerations. Ophthalmic Physiol Opt 1999; 19: 103-111.

76 Flitcroft DI. A model of the contribution of oculomotor and optical factors to emmetropization and myopia. Vision Res 1998; 38: 2869-2879.

77 Atkinson J, Braddick O, Nardini M, Anker S. Infant hyperopia: detection, distribution, changes and correlatesoutcomes from the cambridge infant screening programs. Optom Vis Sci 2007; 84: 84-96.

78 Saunders KJ. Early refractive development in humans. Surv Ophthalmol 1995; 40: 207-216.

79 Flitcroft DI. The complex interactions of retinal, optical and environmental factors in myopia aetiology. Prog Retin Eye Res 2012; 31: 622-660. 